$\mathrm{Oz}$

Volume 13

Article 14

$1-1-1991$

\title{
The Concreteness of The Invisible
}

Tony Duncan

Bryan Zimmer

Todd Devin Powers

See next page for additional authors

Follow this and additional works at: https://newprairiepress.org/oz

Part of the Architecture Commons

c) (1) (9)

This work is licensed under a Creative Commons Attribution-Noncommercial-No Derivative Works 4.0 License.

\section{Recommended Citation}

Duncan, Tony; Zimmer, Bryan; Powers, Todd Devin; Holler, Gary L.; Skaggs, Bradley; and Johnson, Bruce A. (1991) "The Concreteness of The Invisible," Oz: Vol. 13. https://doi.org/10.4148/2378-5853.1226

This Article is brought to you for free and open access by New Prairie Press. It has been accepted for inclusion in Oz by an authorized administrator of New Prairie Press. For more information, please contact cads@k-state.edu. 


\section{The Concreteness of The Invisible}

\section{Authors}

Tony Duncan, Bryan Zimmer, Todd Devin Powers, Gary L. Holler, Bradley Skaggs, and Bruce A. Johnson 


\section{Tony Duncan \\ Bryan Zimmer}

Todd Devin Powers/Gary L. Holler

Bradley Skaggs/Bruce A. Johnson

Critic: Vladimir Kristic
With cities, it is as with dreams: everything imaginable can be dreamed, but even the most unexpected dream is a rebus that conceals a desire or, its reverse, a fear. Cities, like dreams, are made of desires and fears, even if the thread of their discourse is secret, their rules are absurd, theirperspectives deceitfuh and everything conceals something else.

\section{Italo Calvino}

The project commenced with the assumption that the manifested physical form of city (the one which we verify through common perception as objectivization of the idea of city) is a deception. Its deceptiveness resides in two facts: first that it in itself conforms with an organizational principle (a scheme or a pattern) which sustains an "urban" idea on two-dimensional level independent of three-dimensional reality -hence the city we "see" and the city the physically really is are two incongruent things. The second fact is the individuality and non-compliance of architectural forms which bear silent traces of desires and dreams about unfulfilled (or indefinitely postponed) urban future, and which, by the omission and incompletion, continue to mark the alternative to the existing form of city rejecting it as a final and real thing. So it can be argued that the perceived form of city (one which agrees with a particular "urban" idea) is only tentatively real, and it is made so by other "city forms" and other "ideas of city" implicit in it which (if only hypothetically) suggest indeterminancy of the "final" resolution. in order to provide a plane at which it can be concretized as an idea, has to propose and articulate a particular concept (or condition) of city whose plausible reality becomes testing ground for its act(s). Consequently, in the context of architecture, the ideological and physical aspects of city form (on the concrete location) have to be made subject of critical de/reconstruction analysis aimed at unraveling intrinsic urban conditions which delineate territory and topography of an "original" (real?) idea of city. The field of architectural inquiry thus becomes defined by the need to, though its own measure and means, reconfigure and construct the (idea of) city affixing it as a point of reality against which its own meaning will be sought and projected.

We have in the context of this exercise assumed that city as an artifact is a complex entity whose reality cannot be objectified through generalization; its artifactual reality can only be apprehend through the acts of architecture- the veracity of architectural propositions is predicated on the recognition of city as a concrete idea and form which is invoked a affirmed in the process of its making. In this sense we have argued that architecture is a means of interpreting and concretizing the idea of city. The "construction" of the idea of city was in the context of this project provided through two iterative operations. The first one was an interpretative study of the given site and city concentrated on the unraveling of the intrinsic urban conditions which could suggest and enable (Urban) architecture, on the other hand, for such a "construction". The second operation involved introduction of a narrative, a proposition of a fictitious idea of city as a concept of a whole-the invisible counterpart of the real site-that was to be sought after and refereed to in the design process. The actual urban structure which was the subject of the design had to be defined in its function and use as an integral part of the "fictitious" city. The book, Invisible Cities, by Italo Calvino was used as a source of the narrative, either by adopting one of the stories from the book or by creating a new story which was to be inspired by the book's idea.

\section{Tony Duncan}

The idea of Manhattan as a city stems from the notion of displacement. The historical contexts of the city manifests this through the relocation of the Potawatomi Indians, the stranded founders of Manhattan, as well as the disappearance of the native Buffalo from the hills and grasses of the Konza Prairie. Tornados, snow storms and floods erase the images of yesterday, reminding us of man's impermanence.

The weather station has been displaced from the prairie to stand within the city as an epitaph to what the midwestern city was and it's present condition. Station VY6 is designed to react to the environment and the impermanence of weather by moving in relation to the prairie winds. The extent of the building's arc of movement across the site, is limited by the imposed city grid as a depiction of the
VY6's displacement from a location that permitted free movement.

At various times throughout the year, weather balloons are launched in order to gather atmospheric data which is transmitted back to station and the people of Manhattan, who will stand on platforms, in a pit below the station. The pit is a vehicle of displacement for the dwellers of the city separating them from what is around The city is encapsulated within the weather station. The displacement of the object can be seen in it's form, as it attains autonomy through the lack of approach, entry, or specific axis. The fortress like form denies understanding of it's operation or creation.

The only person to inhabit Station VY6 is the weather forecaster whose sole responsibility is to operate the weather station and release of weather balloons. The forecasters identity is unknown, for he is displaced within VY6 never to be seen. The only acknowledgement of his existence is the operation of VY6.

The ideology of the modern city is incapsulated within the building. The building become an artifact that contributes to the exploration of the past. Architecture becomes a facility that gives meaning to man's existence. Through human attempts to order nature, he place himself above other living organisms. Station VY6 is the realization that human existence is not accidental, but intended to have purpose and meaning 


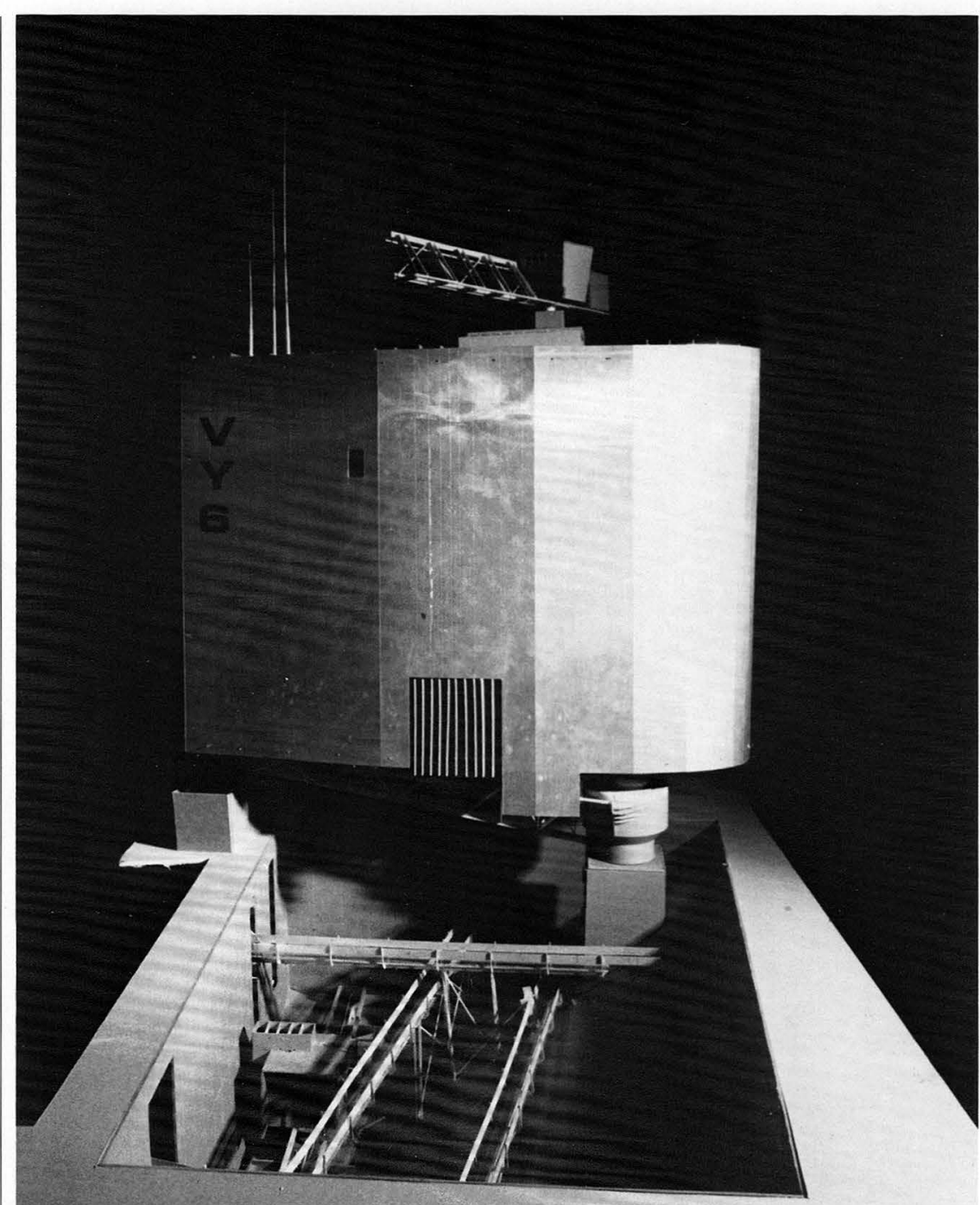

View of Model

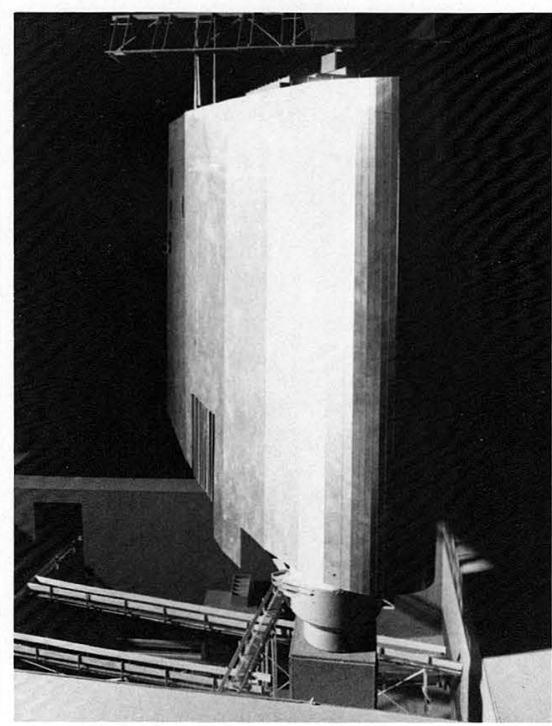

View of Model

\section{Bryan Zimmer}

"A Tower for the City of Manhattan".

The city of Manhattan lies precariously in a valley, located downstream of a reservoir, whose dam is constructed on a fault of the Earth's crust.

A city which owes its origins to the river, a river which has ravished it five separate times. Each time the citizens' rebuilt the institutions with great vigor.

The temporal existence of man is amplified in the city of Manhattan due to this geographic location. The tempora existence is denied by the architecture and the philosophy of the city. Man and his institutions continue to build and dwell with a false sense of stability and security.

The project proposes a link between man and his institurions of city, street and room with the intangible and unmeasurable powers of nature.

The placement of a city-meeting hall above the city will provide a visual connection between the city, due to its height, river, and the reservoir. "The Tower for the City of Manhattan" strives to realign those who dwell in Manhattan with nature.

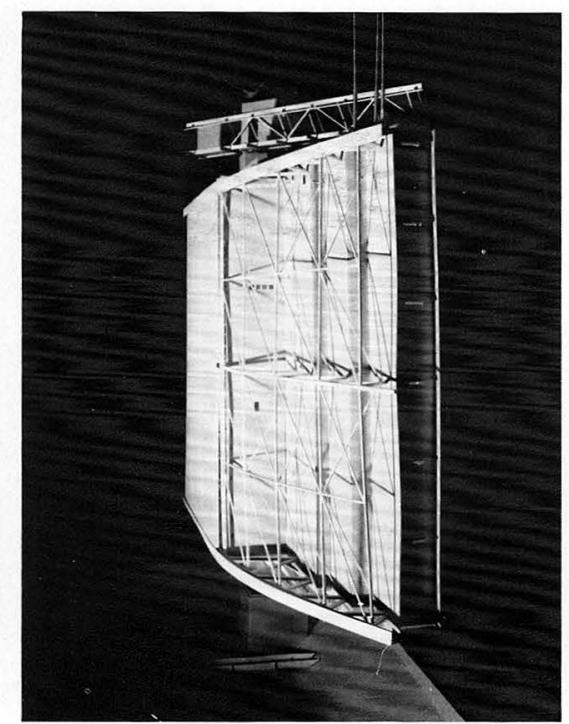

View of Model

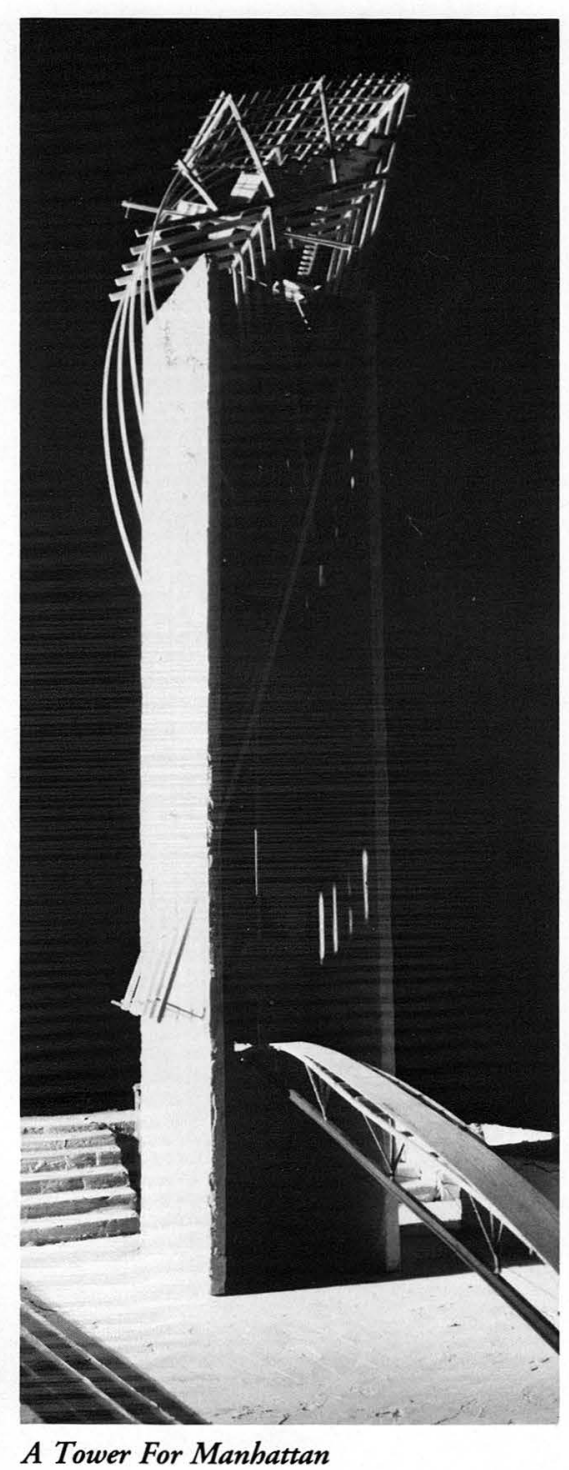

A Tower For Manhattan

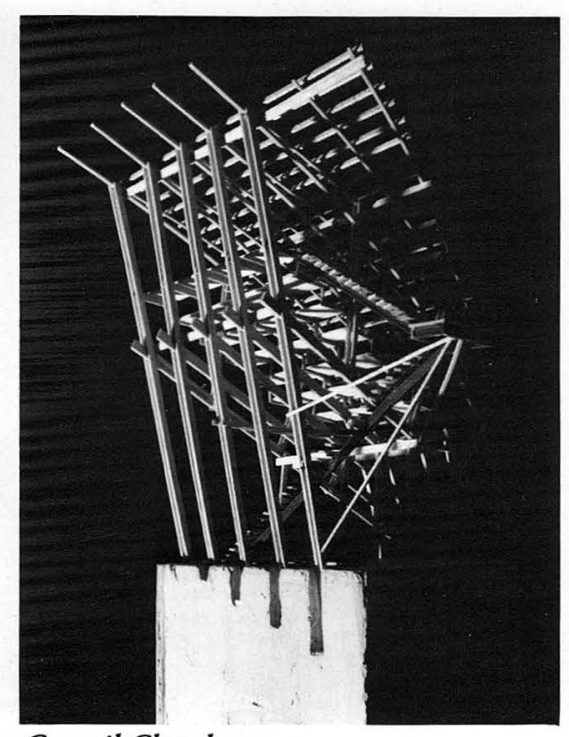

Council Chambers 


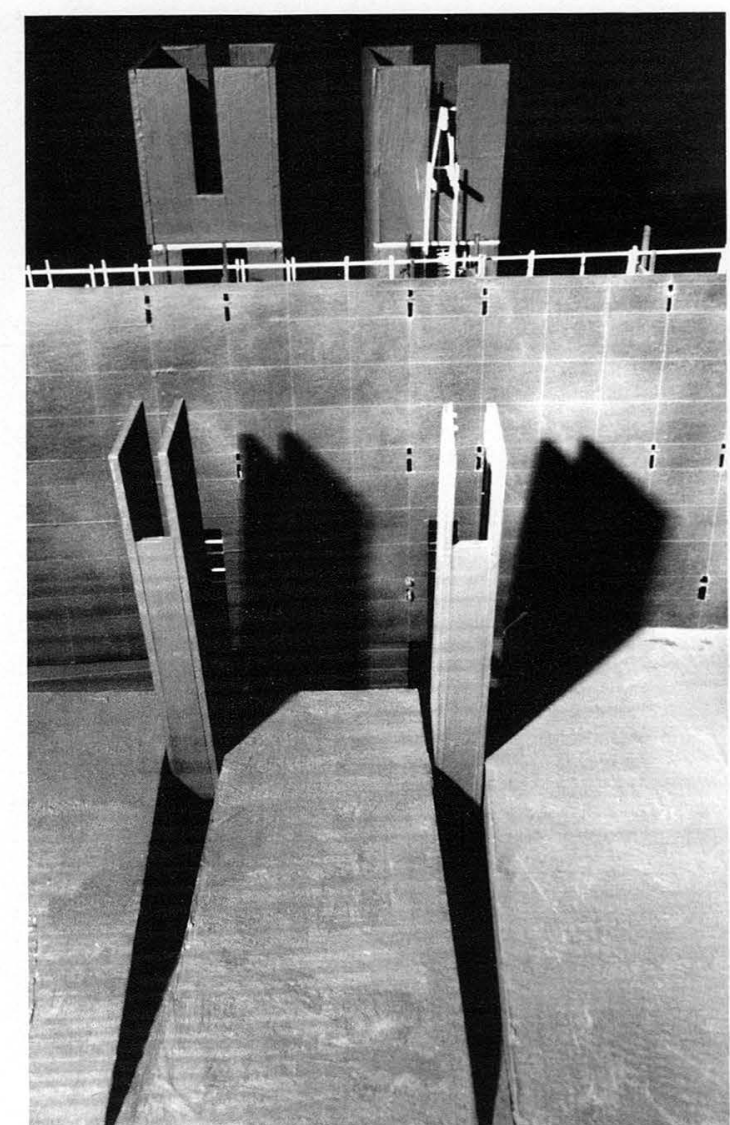

View of Model

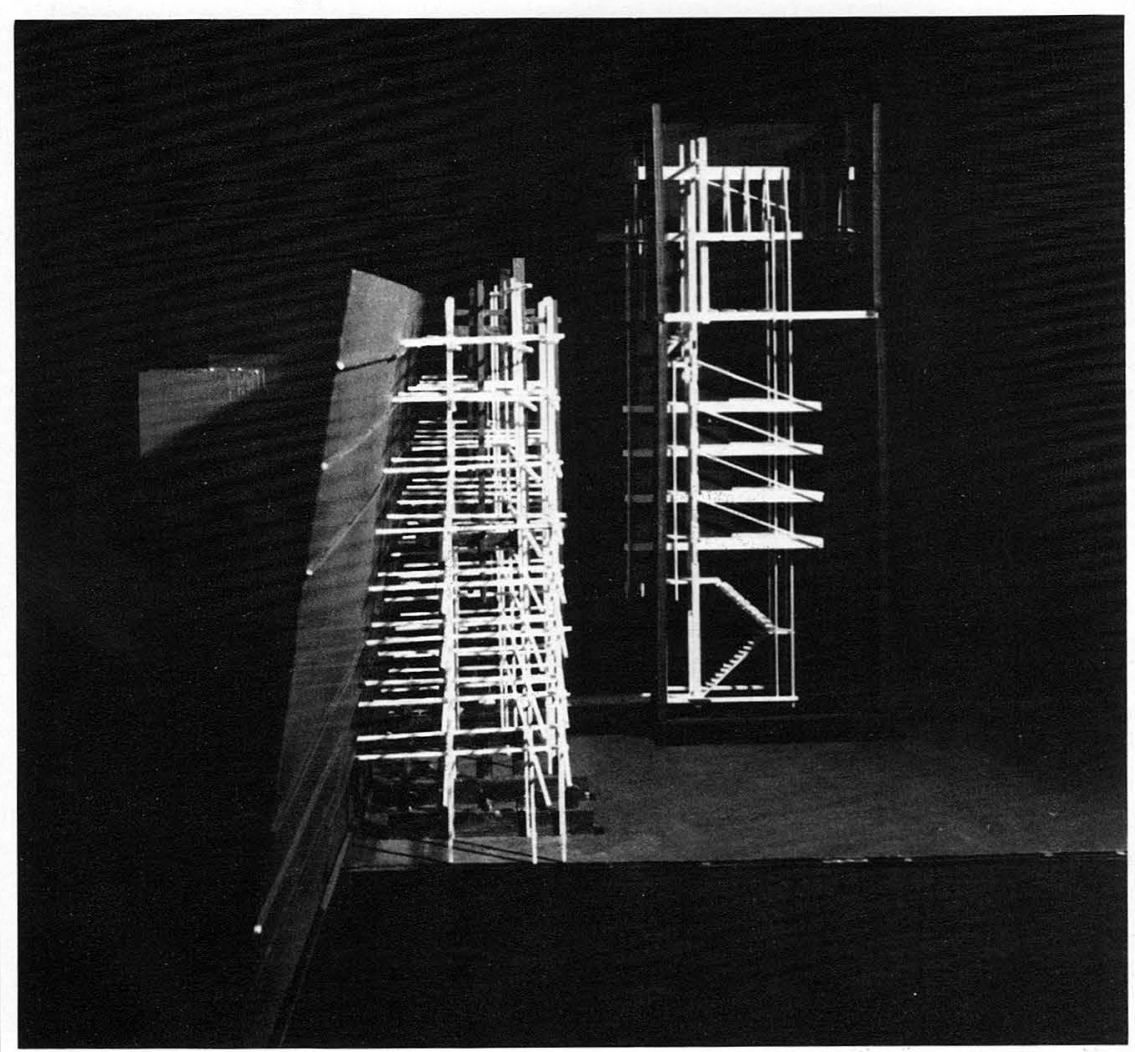

56

View of Model

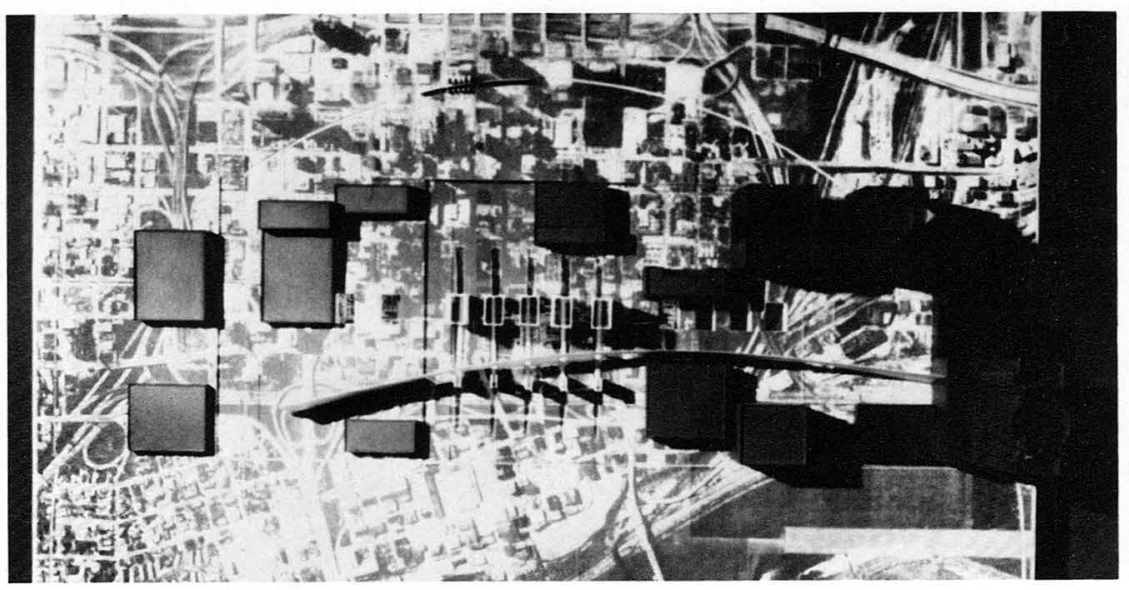

Site Model

Todd Devin Powers/Gary L. Holler

What is dwelling in the city?

From Invisible Cities by Italo Calvino, "The inferno of the living is not something that will be; if there is one, it is what is already here, the inferno where we live everyday, that we form by being together. There are two ways to escape suffering it. The first is easy for many: accept the inferno and become such a part of it you can no longer see it. The second is risky and requires constant vigilance and apprehension: seek and learn to recognize who and what, in the midst of the inferno, are not inferno, then make them endure, give them space."

We propose that between the ideal American city ordering system (grid), and the intrinsic (current) condition, there exists memory; the third city.

The architectural response to the present morphological condition in downtown Kansas City occurs at two levels: a general urban response and at a more site specific response.

An urban response arises from a historical, morphological, and textual study which reveals several significant conditions of city. Historical analysis identifies a geopolitical and topographic high point at the center of early 19th century Kansas City. however the connection to these beginnings is not intelligible when viewing present downtown Kansas City.
Morphological study reveals a dualistic condition of becoming and decaying within the city. The site exhibits characteristics of being both the edge of downtown and a transition zone between city and suburbia.

Initiated by these discoveries, the necessity for reconnection of the city to its origin (the center) became apparent. To recreate this connection in the present decentered relationship of man to suburbia and to city, the collective memory of a meaningful center was inscribed upon the site.

Dwelling-the realization of place in rela tion to the cosmos at all scales.

To dwell-to make ones home.

To make-to bring into being, create, in vent.

Werner Ruhnau has described dwelling as, "to want means to invent, to this wanting is added the will to live what one has invented."

The wall exists as an arc of a circle drawn around the city with its inherent center at the origins of Kansas City. The tower is transposed on either side of the wall creating a confrontation between city and suburbia. Those who inhabit the tower are capable of viewing only the wall, re-establishing their memory of center, thereby allowing one to dwell. 


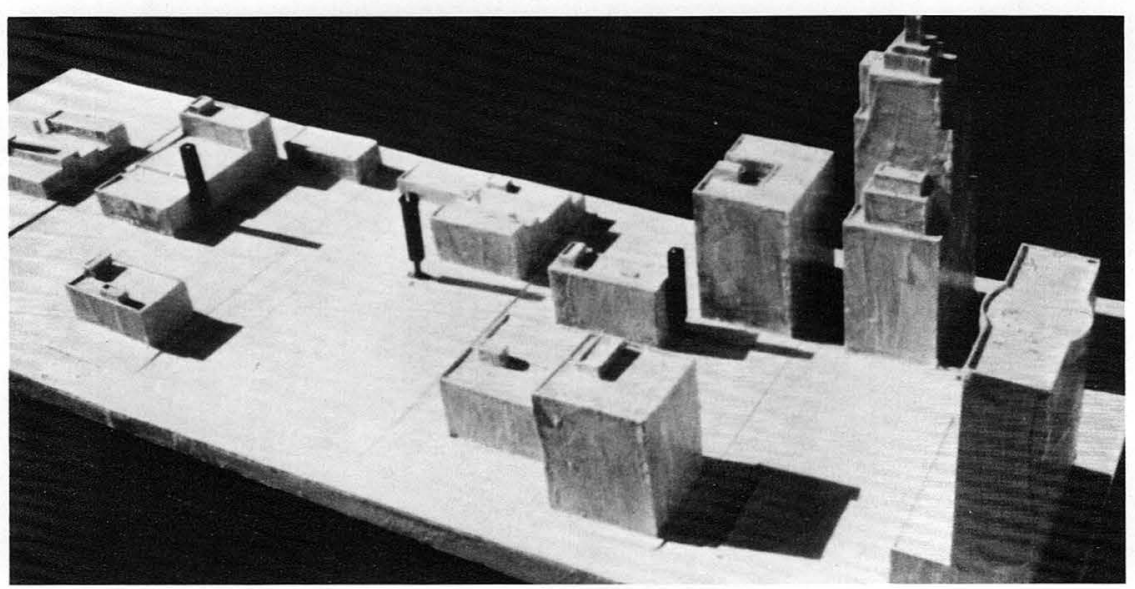

Site Model

Bradley Skaggs/Bruce A. Johnson

Kansas City is a unique city in that it originated in the temporality of the United States expansion from east to west. It was a city to pass thru, much as the meandering of the two rivers it is founded near. In today's highly mobile society, K. C. stands unique in its lack of nationality. The city can be seen as both place and place less. A city, one can easily leave, and one that can be comfortably lived in. This makes K. C. both functional and flexible to its users/ dwellers. From the realization of the potential of the city in terms of both its users and environment comes interpretation. Interpretation allows for the potential to understand both the city and the notion of dwelling, through memory. Memory allows for the city be revealed to the user/ dweller.

Revelation is the act of understanding through the revealing of certain aspects which define that which is being revealed. Revelation by interpretation allows for an understanding of that which is, but not obviously understood; the city itself. Revelation can be both subtle as well as dramatic and occurs where potential to interpret is realized or found(out). Finding out is one of discovery, for discovering itself speaks of revelation and the interpretation of the unknown.

Referencing can be seen as the device by which man can order the unknown through select objects within the environment. Referencing is rooted in the ability

to remember. The identification of something then becomes the memory of that thing-a reference or a known within the unknown. Through referencing man, in the midst of his temporal nature, he can begin to establish order within the unknowns of his existence and the uncertainty of his death. Referencing then begins before birth, in the assumption of the fetal position, a static seated posture, within a mobile body. The act of dwelling then becomes the act of referencing or attempting to interpret the general nature of the universe, and mans place in it.

Dwelling is the attempt of understanding existence through the revelation of the cosmos. The interpretation of the cosmos and the subsequent referencing of them is mans attempt to rationalize his temporal existence. Dwelling then becomes the referencing of a known position within the unknown.

What is "to dwell"?

The potential to understand dwelling is provided through the placement of architecture within the site. Placement occurs so as to provide minimal intervention. The architecture is placed within the alleys of the site; the neglected city. Placed along an east-west axis, the architecture is perpendicular to true geographic north. The existing layout of the city is $3^{\circ}$ west of true north with the most accurate street being State Line Blvd. The architecture provides compensation for the earth's tec-

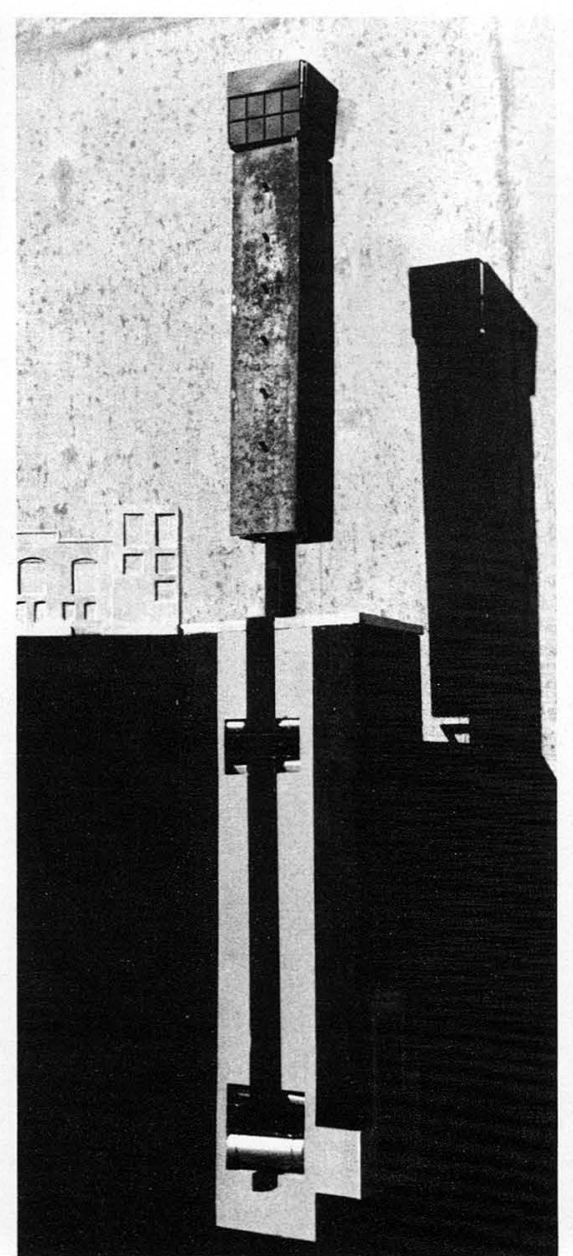

View of Model

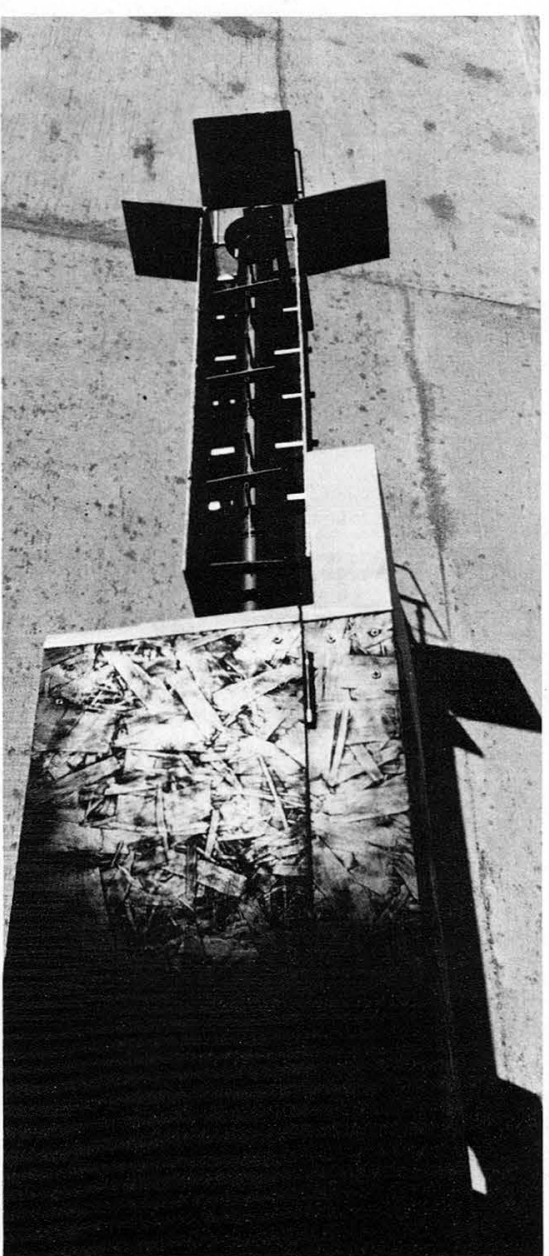

View of Model

tonic movement of $3 \mathrm{~cm}$ per year, thus insuring a fixed position relative to true north. The architecture remains autonomous to the city and becomes a series of objects to be found (out) and explored. In their exploration, one is asked to interpret and remember. The provision to interpret allows for revelation and memory through the discovering of one's position relative to a fixed point of reference. When searching through the architecture, one will emerge within the scaleless confines of a space and is forced to cling to his only anthropomorphic reference; simple furniture. The furniture both orients the user to a fixed point and saves him from the unknown of the space. The furniture thus becomes his reference to existence. Once positioned and completely static upon either the chair, bed, desk, or toilet, he has the power to both reveal and interpret the city and the non-visual fixed point of reference beyond the city. Once experi- enced and remembered, the architecture becomes a reference within the changing world. The architecture provides tension to this change in two ways; first, the movement of existing structures toward the architecture, and second, by the opening up of the chasm behind the architecture. This forces the user/dweller to intervene by judging the worth of the architecture as a reference to be cherished, destroyed, or remembered.

The site consist of a unique group of buildings ranging from a sole skyscraper, to simple one and two story structures. The change of the site has evolved from a more densely built environment to its present state of scattered buildings on a sloped parking lot; a remembrance of what was. The site today is alive with signs of its past and present, signs which speak of what dwelling is and was. 